This is an electronic reprint of the original article. This reprint may differ from the original in pagination and typographic detail.

Author(s): Pihlainen, K.; Santtila, M.; Häkkinen, Keijo; Kyröläinen, Heikki

Title: $\quad$ Associations of Physical Fitness and Body Composition Characteristics With Simulated Military Task Performance

Year: $\quad 2018$

Version:

Please cite the original version:

Pihlainen, K., Santtila, M., Häkkinen, K., \& Kyröläinen, H. (2018). Associations of Physical Fitness and Body Composition Characteristics With Simulated Military Task Performance. Journal of Strength and Conditioning Research, 32(4), 1089-1098. https://doi.org/10.1519/JSC.0000000000001921

All material supplied via JYX is protected by copyright and other intellectual property rights, and duplication or sale of all or part of any of the repository collections is not permitted, except that material may be duplicated by you for your research use or educational purposes in electronic or print form. You must obtain permission for any other use. Electronic or print copies may not be offered, whether for sale or otherwise to anyone who is not an authorised user. 


\section{Associations of physical fitness and body composition characteristics with simulated military task performance}

Pihlainen $\mathrm{K}^{1}$, Santtila $\mathrm{M}^{2}$, Häkkinen $\mathrm{K}^{3}$ and Kyröläinen $\mathrm{H}^{2,3}$

${ }^{1}$ Defence Command, Finnish Defence Forces, Helsinki, Finland

${ }^{2}$ National Defence University, Helsinki, Finland

${ }^{3}$ Department of Biology of Physical Activity, University of Jyväskylä, Jyväskylä, Finland

Correspondence: Kai Pihlainen

Address: Defence Command Finland, J7, Human Performance Sector, Fabianinkatu 2 F, 00130, Helsinki, Finland (Europe)

Email (1): kai.pihlainen@mil.fi, (2): kai.pihlainen@gmail.com

Tel: +358400248910, +358299510173 


\section{ABSTRACT}

The purpose of the present study was to evaluate the associations of physical fitness and body composition characteristics with anaerobic endurance performance, tested in the combat load using the occupationally relevant military simulation test (MST). Eighty-one male soldiers, deployed to a crisis management operation in the Middle East, volunteered for the study and participated in a test battery consisting measurements of muscle strength, body composition characteristics, endurance capacity, and MST.

A Spearman correlational analysis revealed that the strongest variable, correlated with MST time, was the countermovement jump performed with the combat load (CMJ2) $\left(r_{s}=-0.66, p<0.001\right)$. Among the individual body composition variables the MST time had the strongest relationship with fat percentage $\left(r_{s}=0.53, p<0.001\right)$ and skeletal muscle mass $(\mathrm{SMM})\left(r_{s}=-0.47, p<0.001\right)$. The use of the dead mass ratio, which was calculated dividing body mass by fat mass accompanied with the weight of the combat load, increased body composition-based associations significantly, and this variable turned out to be the best single predictor for the MST performance $\left(r_{s}=-0.67, p<0.001\right)$. Significant predictors of the MST time in the stepwise multivariate regression analysis included CMJ2, 3000m, SMM and push-ups. Together, these variables explained $66 \%\left(\mathrm{R}_{\text {adj }}^{2}=0.658\right.$, model $p<0.001)$ of the variance in the MST time.

In conclusion, the novel MST is a promising military specific assessment method of muscle power of the lower extremities as well as endurance capacity which are crucial performance components in anaerobic combat situations.

Keywords: Obstacle course, anaerobic performance, soldier 


\section{INTRODUCTION}

Military occupations include a variety of demanding tasks that require a certain level of endurance capacity combined with muscular strength ${ }^{42,21,15}$. Commonly these physical fitness components are tested as a part of military recruitment, selection processes or regular follow-up of readiness ${ }^{39,33}$. Traditionally, the physical performance of soldiers has been tested by population-based endurance and muscular fitness tests such as a 12-minute running test and push-ups in one or two minutes ${ }^{41,22}$. However, army soldiers engaged with combat situations, require an adequate level of anaerobic capacity to perform high-intensity assignments in rapidly changing life-threatening situations. Commonly soldiers are performing such assignments with combat load consisting of a personal weapon, combat gear, protective components and other equipment of the unit ${ }^{35,43}$. Such highintensity tasks typically include sprinting, rushes, climbing, quick changes in movement directions, jumping, crawling, lifting and carrying loads and casualty evacuation ${ }^{35}$.

Relevance of the basic fitness tests to combat readiness has been questioned in a number of studies, and it has been argued that such health-related fitness tests favor soldiers with low body mass and high relative endurance capacity ${ }^{3,45,46}$. Indeed, most of the basic fitness tests are conducted in light sports clothing and yet, many operational military tasks are often performed wearing combat gear and a body armor which increase the weight of the load carriage ${ }^{21}$. The increase in weight of the carried load influences negatively to the physical performance of soldiers during tasks of longer ${ }^{13}$ and shorter ${ }^{26,28,19}$ duration ${ }^{11}$. Therefore, it can be hypothesized that less body fat ${ }^{13,25}$ and larger fat free mass ${ }^{25}$ are beneficial body composition factors in such tasks. 
These findings have led to a development of military task related fitness tests that evaluate task specific performance or combat readiness ${ }^{38,44,37}$. Task analysis-based specific tests can be used to improve measurement validity and to study beneficial physical fitness and body composition components in military occupations. Typical occupationally relevant tests include walking or running in various distances in a combat load ${ }^{33,43,3,40}$, manual material handling ${ }^{38}$, lifting and carrying loads ${ }^{10}$ and obstacle courses ${ }^{28,19}$ that include mimicking of tactical movements used in combat situations. These simulations include various military-specific test protocols for testing anaerobic capacity and maneuver abilities of soldiers.

The Finnish Defence Forces has hundreds of soldiers serving in several crisis management operations around the world. Despite the fact that the nature of crisis management operations is peacekeeping, and not combat, all soldiers are in a risk of facing hostile actions during their deployment. The most probable scenario in the Middle East would be an attack outside the military camp starting with a road side bomb or other intelligent explosive device and a following fire contact with an enemy group. This scenario would lead to immediate life threatening situation and the actions required for the soldiers to survive would be anaerobic ones from the physiological perspective. However, currently there are no specific field tests for evaluation of anaerobic performance of the crisis management soldiers in Finland. Such test, implemented to a test battery with physical fitness and body composition measurements, would bring new insights to the interrelationships between the measured variables and thus, could be utilized for development of more optimized physical training programs for soldiers preparing for deployment ${ }^{9,31,16}$. With this in mind, the purpose of the present study was to evaluate the associations of physical fitness and body composition characteristics with simulated high-intensity military task performance. 


\section{METHODS}

\section{Experimental Approach to the Problem}

A novel field expedient military simulation test (MST) was implemented to a test battery of the research project conducted in the Middle East to study the anaerobic performance of soldiers and the interrelationships between MST (dependent variable), physical fitness and body composition variables. The research project lasted six months but the focus of the present study was on the results of the initial measurements. All measurements were conducted during the deployment in a military base in South Lebanon after a two-week acclimatization period. The MST was designed in collaboration with physical training experts and professional soldiers. The test consisted of maneuvers and tasks which might, according to the previously described scenario, be probable in an ambush situation during a patrol or transport in the deployment area. In addition, prior studies focusing on military tasks and simulations were taken into account during the development of MST $17,26,28,31,32,42$

Body composition characteristics and strength variables were measured during the first test day. The endurance capacity was tested on the second and MST on the third test day. A minimum of one day for recovery separated the test days. Acute responses of the MST performance were examined to estimate the stress level of soldiers induced by MST. A cross-sectional correlational design and stepwise multivariate regression analyses were used to investigate the relationships between selected body composition and physical fitness parameters, and MST time. 


\section{Subjects}

More than 250 soldiers were deployed for 6 months in the crisis management operation in the Middle East, and 81 male soldiers without physical limitations took voluntarily part in the present study. Before the deployment, the soldiers were examined by a physician. The mean \pm SD (range) age, height, weight, body mass and body mass index (BMI) of the soldiers were $29.8 \pm 8.0$ (20.4-51.2) yrs, $179.8 \pm 6.3(166.3-199.2) \mathrm{cm}, 79.2 \pm 8.5(58.5-105.6) \mathrm{kg}$, and 24.5 $\pm 2.3(18.5-31.0)$ $\mathrm{kg} \cdot \mathrm{m}^{2}$, respectively. The study was approved by and conducted in accordance to the statement of the Ethical Committee of the Central Finland Health Care District. The soldiers were informed of the benefits and risks of the investigation prior to signing an institutionally approved informed consent document to participate in the study.

\section{Procedures}

All measurements were carried out after a two-week acclimatization period inside the military base in South-Lebanon. The clothing conditions were light underwear in the body composition measurements and shorts, T-shirt and indoor or running shoes in the strength and endurance performance measurements.

The measurements of body composition characteristics were conducted in the morning after an overnight fast at a military hospital. Body height was measured by using a wall-mounted height board (Seca Bodymeter 206, Seca GmbH \& Co, Hamburg, Germany). Body mass (BM), skeletal muscle mass (SMM), fat mass (FATM) and fat percentage (FAT\%) were determined by using the segmental multi-frequency bioimpedance analysis assessment (InBody 720, Biospace Co Ltd, Seoul, South Korea) in accordance with the manufacturer's guidelines. 
Dead mass ratio (DMR), adopted from Lyons et al ${ }^{30}$ was calculated dividing BM by FATM accompanied with the weight of the carried combat load. In the original study by Lyons et al ${ }^{30}$, DMR was calculated from lean body mass but in the present study from BM as follows:

Dead mass $(D M, \mathrm{~kg})=$ FATM + weight of the combat load, excluding assault rifle

Dead Mass Ratio $(D M R)=\frac{B M}{D M}$

Maximal isometric force of the lower $\left(\mathrm{MVC}_{\text {lower }}\right)$ and upper $\left(\mathrm{MVC}_{\text {upper }}\right)$ extremities' extensor muscles were measured bilaterally in a sitting position by using electromechanical dynamometer ${ }^{18}$ (University of Jyväskylä, Jyväskylä, Finland) modified from a David 210 dynamometer (David Fitness and Medical, Helsinki, Finland). In the lower extremity measurement, the seat was adjusted to maintain knee and hip angles of $107^{\circ}$ and $110^{\circ}$, respectively. In the upper extremity measurement, the handle bar was adjusted to the height of shoulders and seat to maintain elbow angle of $90^{\circ}$. In both tests, the soldiers were instructed to exert their maximal force in all three trials which were separated by a minimum of 30 seconds for recovery. The best performances with regard to maximal force output in both tests were selected for further analysis.

Standing long jump (SLJ) was used to assess explosive force production of the lower extremities ${ }^{8}$. Before the minimum of three test attempts, the soldiers were instructed a proper technique and five to seven warm-up trials were provided. The jumps were performed on a 10-millimeter-thick plastic mattress designed for the purpose (Fysioline Co, Tampere, Finland). The jumps were performed from a standing position, feet at pelvis to shoulder width. Explosive bilateral take off was assisted by powerful extension of the hip and swinging of the arms. The landing was performed bilaterally 
and falling backwards led to disqualification of the attempt. The result of the best jump was expressed as centimeters of the shortest distance from the landing point to the starting line.

The dynamic muscle endurance capacity of trunk and upper extremities were assessed by using situp, push-up and pull-up tests, respectively. A test supervisor showed the correct technique for each performance before each test. The soldiers were also informed that after a notice from the supervisor incorrect repetitions would not be calculated to the test result.

Sit-ups were used to measure performance of abdominal and hip flexor muscles ${ }^{47}$. In the starting position, the soldier laid on his back while legs were supported from the ankles by an assistant. The knees were flexed at the angle of $90^{\circ}$, elbows pointing upwards and fingers crossed behind the back of the head. One successful repetition was determined when the soldier lifted his upper body from the starting position and brought elbows to the knee-level. The result of the test was expressed as a number of consecutive successful repetitions during 60 seconds.

The push-up test was to measure performance of arm and shoulder extensor muscles ${ }^{1}$. Before taking a starting position, the soldier laid face down on the floor, feet parallel at pelvis to shoulder width and hands positioned so that thumbs could reach the shoulders while other fingers pointing forward. Before the initiation of the test, the soldiers were instructed to extend their arms to the starting position and keep the feet, trunk and the shoulders in the same line throughout the test. One successful repetition was counted when the soldier lowered his torso by flexing arms to an elbow 
angle of $90^{\circ}$ and returned to the starting position by extending his arms. The result of the push-up test was expressed as a number of consecutive successful repetitions during 60 seconds.

The pull-up test was used in order to measure the performance of arm and shoulder flexor muscles. In the starting position, the soldiers hang by their hands from a horizontal bar, arms and feet straight. The underhand grip was instructed to be at shoulder width, and the hip and legs to be extended throughout the test. One successful repetition was performed when the body was raised by flexing arms from the starting position until the chin was above the bar. The result of the test was expressed as a number of consecutive pull-ups until volitional exhaustion.

Endurance performance was evaluated by using the 3000-meter running test. The test was performed on a standardized $1.13-\mathrm{km}$ track covered with asphalt. The total ascent and descent of the track was 32 meters. The soldiers were instructed to complete the test with their maximal effort and in the shortest possible time. The duration of performance was recorded with a stopwatch and heart rate (HR) was recorded throughout the test by the memory belt (Memory belt, Suunto, Vantaa, Finland). Peak heart rate ( $\left.\mathrm{HR}_{\text {peak }}\right)$ was determined by a computer analysis software (Firsbeat PRO, Firstbeat Technologies, Jyyäskylä, Finland) as the highest recorded HR during 3000 m.

MST consisted of typical army soldier maneuvers and tasks. The test was performed on an artificial grass court wearing a combat dress uniform, leather boots and combat gear including a body armor, helmet and assault rifle replica $(3 \mathrm{~kg})$. From the starting position of lying supine, the soldiers performed four consecutive $6.2 \mathrm{~m}$ rushes changing direction after each rush. After the last rush the soldiers continued 11.3 meters by low crawl, followed by a sprint of $21.8 \mathrm{~m}$. After the sprint, the 
soldiers ran another $21.8 \mathrm{~m}$ jumping over three $40 \mathrm{~cm}$ obstacles (Movemakers Step, Movemakers, Tiistenjoki, Finland) separated by a distance of $5 \mathrm{~m}$. Thereafter, the soldiers lifted, carried and lowered two $16 \mathrm{~kg}$ kettlebells (Eleiko Co, Halmstad, Sweden) four times for a distance of 2.5 meters. This was followed by a zig zag run of 42.4 meters. Finally, before sprinting back to the starting line the soldiers dragged a $65 \mathrm{~kg}$ mannequin (Ultimate sandbag, Ultimate sandbag training, Scottsdale, AZ, USA; two sandbags, attached to each other with cable ties) for a circle of 24 meters. The total length of the MST track was 242.5 meters (figure 1A and B).

Figure $1 A$ and $B$ about here, please

Preceding MST, a saliva sample was obtained from all soldiers by using cotton swab according to the manufacturer's guidelines (Salivette, Sarstedt, Nümbrecht, Germany), and blood lactate (BLa) was measured from the fingertip (Accutrend Plus, Roche Diagnostics GmbH, Mannheim, Germany) from 59 randomly selected soldiers. Thereafter, the soldiers rated their perceived exertion (RPE) ${ }^{7}$ and performed three countermovement jumps (CMJ) on a force platform (FP8, HUR Labs, Oulu, Finland) both in their underwear (boxers, t-shirt and socks; CMJ1) and in the combat load excluding the rifle replica (uniform, boots, helmet, body armor, modular vest; CMJ2). The soldiers were allowed $30 \mathrm{~s}$ for recovery between the jumps in both clothing conditions. CMJ data were automatically transported to a computer software (Force Platform Software Suite, HUR Labs, Oulu, Finland), and jump height was calculated from the take-off velocity.

Before the MST performance, each soldier was individually familiarized with the track by a supervisor who also gave verbal instructions during the test. The soldiers were instructed to 
complete the track in a shortest possible time. The performance time was recorded by a stopwatch and HR by a memory belt (Memory belt, Suunto, Vantaa, Finland).

RPE and saliva sampling were repeated within one minute after the termination of MST.

Immediately after giving the saliva sample, the soldiers performed another three CMJs in the combat load excluding the assault rifle replica (CMJ3). Finally, BLa was obtained 5 minutes after the test.

The saliva samples were stored at $-20^{\circ} \mathrm{C}$ until they were transported in a frozen state for further analysis. The samples were thawed and centrifuged at $3500 \mathrm{rpm}$ for $10 \mathrm{~min}$. Saliva cortisol (saCOR) and alpha-amylase (saAA), as potential non-invasive biomarkers of exercise-induced stress $^{6}$, were analyzed. SaCOR was analyzed by Immulite 2000 XPi (Siemens Healthcare, Llanberies, UK) using chemiluminescent enzyme immunoassay kits, while saAA assays were performed by Konelab 20XTi (Thermo Fisher Scietific, Vantaa, Finland) using the enzyme photometric measurement method (inter-assay CV $13.2 \%$ and $3.2 \%$, respectively).

\section{Statistical analyses}

Commercial software (IBM SPSS 22.0.0.0, Chicago, Illinois, USA) was used for statistical analyses. Descriptive statistical methods were used for the calculation of means and standard deviations (SD). Significance of the relative differences between variables measured prior to and post- MST were analyzed by using One-Sample Wilcoxon Signed Rank Test, due no non-normality and outliers. 
The associations between MST and other measured variables were tested for linearity with Spearman's product moment correlation coefficients. Stepwise multivariate regression analyses were used to model log-transformed MST. The $p<0.05$ was used to establish statistical significance. Post hoc power for high correlation $(n=81, r=0.5)$ was 0.998 , and for moderate correlation $(n=81$, $r=0.3) 0.781$.

\section{RESULTS}

The mean $( \pm \mathrm{SD})$ results of the body composition and physical fitness measurements are presented in table 1 .

Table 1 about here, please

The mean $( \pm$ SD) MST performance time was $148 \pm 22$ s (range $100-214 \mathrm{~s}, n=81)$. The average HR ( $n=64$ ) during the test was $169 \pm 11 \mathrm{bpm}$ (range of means $146-185 \mathrm{bpm}$ ) or $90 \pm 4 \% \mathrm{HR}_{\text {peak }}$ (range of means $\left.80-96 \% \mathrm{HR}_{\text {peak }}\right)$. MST induced three- and fourfold increases in saAA (1 min POST) and BLa (5 min POST), respectively, while saCOR ( 1 min POST) increased by $12 \%$ from the initial measurement. After the MST, the RPE ratings and BLa levels were $18 \pm 1$ and $10.8 \pm 3.7 \mathrm{mmol} \cdot \mathrm{L}^{-1}$, respectively. The acute PRE-POST responses of the variables are presented in table 2. 
Table 2 about here, please

Prior to MST, RPE was rated and CMJ performed twice; in a light underwear and again in the combat load $(19.5 \pm 1.0 \mathrm{~kg})$. The weight of the combat load increased RPE by $14 \pm 22 \%(p<0.001)$ from $10 \pm 2$ to $12 \pm 2$ and reduced the $\mathrm{CMJ}$ performance by $25 \pm 5 \%(p<0.001)$ from $37.8 \pm 6.1$ to $28.5 \pm 5.1 \mathrm{~cm}$. The Spearman correlation analysis showed that the strongest individual predictor of the MST performance was explosive force production of the lower extremities, especially CMJ2 $\left(r_{s}\right.$ $=-0.66, p<0.001)$ (figure 2).

Figure 2 about here, please

Furthermore, all four variables assessing muscle power of the lower extremities were among the top five strongest associations with MST. In addition, the correlation between CMJ2 and SLJ was high $\left(r_{s}=0.81, p<0.001\right)$. Among individual body composition variables, MST had strongest correlations with FAT\% $\left(r_{s}=0.53, p<0.001\right)$ and SMM $\left(r_{s}=-0.47, p<0.001\right)$. Body mass $\left(r_{s}=-0.18, p=0.10\right)$ or BMI $\left(r_{s}=0.07, p=0.55\right)$ were not associated with the MST time, while the associations with $\operatorname{FATM}\left(r_{s}=-0.40, p<0.001\right)$ and body height $\left(r_{s}=-0.38, p<0.001\right)$ were moderate. The use of DMR increased body composition-based correlations significantly and this variable turned out to be the best predictor of MST performance $\left(r_{s}=-0.67, p<0.001\right.$; figure 3). The correlations between the MST time and other measured variables are presented in table 3. 
Figure 3 about here, please

\section{Table 3 about here, please}

The stepwise regression analysis showed that four variables (CMJ2, 3000m, SMM and push-ups) were significantly associated with the MST time. Together, these variables explained $66 \%(R=0.82$, $\left.R_{a d j}^{2}=0.658, F(2.495)=38.531, p<0.001\right)$ of the variance in the MST time. CMJ2 independently explained $47 \%$ of the variance in the MST time. The run time in $3000 \mathrm{~m}$ improved the prediction of the model by $13 \%$ (combined $R_{a d j}^{2}=0.608$ ). Significant but minimal improvements were reached by adding SMM (combined $R_{a d j}^{2}=0.633$ ) and finally, push-ups (combined $R_{a d j}^{2}=0.658$ ) to the prediction model. Together, these variables formed a following MST time prediction model: $y=5,201-0,011 \mathrm{x}_{1}+0,001 \mathrm{x}_{2}-0,008 \mathrm{x}_{3}-0,002 \mathrm{x}_{4}$, where $y$ is $\operatorname{MST}(\mathrm{s}), \mathrm{x}_{1}$ is $\operatorname{CMJ} 2(\mathrm{~cm}), \mathrm{x}_{2}$ is $3000 \mathrm{~m}(\mathrm{~s}), \mathrm{x}_{3}$ is $\mathrm{SMM}(\mathrm{kg})$ and $\mathrm{x}_{4}$ is push-ups (repetitions in minute).

\section{DISCUSSION}

The present study demonstrated that the two statistically strongest variables, which were inversely associated with the MST performance, were DMR and CMJ performed in combat load (CMJ2). Furthermore, all variables measuring muscle power of the lower extremities were good predictors for the MST performance. These results are in line with previous studies using job-specific anaerobic task simulations ${ }^{35,31,2}$. The regression analyses revealed that especially the jump height of CMJ2 and 3000m time but also SMM and 1-min push-up test result were significant predictors of the MST performance. Thus, the presented MST is a promising military specific assessment 
method of muscle power of the lower extremities as well as endurance capacity which are important performance components in anaerobic combat situations.

Blood lactate has traditionally been used as a biomarker of exercise intensity but during the last decade, new non-invasive methods to estimate physiological stress during increasing work load have been introduced in a number of studies ${ }^{6,12,14,20,36}$. De Oliveira et al ${ }^{12}$ found strong associations between BLa and saAA during the incremental exercise test and similar findings have been observed in other studies ${ }^{14}$. In the present study, significant increases in RPE, BLa and saAA at the termination of the test indicate that the MST performance was subjectively and physically demanding for the soldiers. However, no associations between acute biomarkers were observed. A moderate but insignificant increase in saCOR was observed after MST. It is possible that the duration of the MST performance was too short to induce acute saCOR responses immediately after the test. Increases in the saCOR has been observed in athletes immediately after but, especially, 30 min after the tests with high intensity endurance exercise lasting $12-15$ minutes ${ }^{20}$ as well as highintensity exercise lasting 15 minutes ${ }^{36}$.

Rushing speed has positively been associated with survivability in military simulations ${ }^{3,5}$. Mala et al $^{31}$ observed a significant inverse relationship between vertical jump peak power measured by $\mathrm{CMJ}(r=-0.66)$ and 5-m sprint time in the combat load $(r=-0.66)$. Both vertical and horizontal jump performances have also been shown to associate strongly with sprinting speed in elite athletes ${ }^{29}$. Furthermore, the finding that the strongest predictor of anaerobic military task course performance was CMJ peak power $(r=-0.67)$ by Mala et $\mathrm{al}^{31}$ is well supported by the present study. Harman et al ${ }^{17}$ tested a number of anthropometric measures and fitness tests for prediction 
models of physical performance in the battlefield. The vertical jump height entered in all prediction equations of four combat specific tests performed with a fighting load (400-m run time, obstacle course time, five 30-m rushes and a simulated casualty rescue). Based on these findings, it can be concluded that explosive power of the lower extremities is essential in anaerobic combat situations.

It has been established that both anaerobic and aerobic metabolic pathways contribute to continuous, near maximal intensity muscle work exceeding two minutes ${ }^{23}$. The association of aerobic capacity and load carriage performance has, however, been found in studies using longer load carriage test protocols ${ }^{40,30}$. In the study of Harman et $\mathrm{al}^{17}$, the second most common variable after the vertical jump, predicting battlefield specific performance was the $3.2-\mathrm{km}$ run which entered three out of the four models, even though the duration of their tests varied between 43 and $84 \mathrm{~s}$. In the present study, the $3000 \mathrm{~m}$ run time associated significantly with the MST time $\left(r_{s}=\right.$ $0.48, p<0.001)$ and improved the stepwise regression model prediction by $13 \%$. Based on previous studies, it is likely that with by increasing the length of the MST track would have increased the correlation between the endurance performance and MST.

External load, typically carried by soldiers in the form of the combat gear, has a negative impact on combative movement performance ${ }^{3,32}$ as well as repeated high-intensity military tasks ${ }^{35,19}$. The results of Jaworski et al ${ }^{19}$ indicate that increasing the relative weight of the carried load decreases combat-related performance capability. Billing et al ${ }^{3}$ investigated the effects of increasing load on susceptibility to enemy fire during tactical combat movements. They found that the duration of exposure to enemy fire during the experiment increased linearly with the increase in external load. Another important finding was, that the decline of performance for the faster subjects was $0.8 \%$ per 
$\mathrm{kg}$ increase in external weight, whereas for the slower subjects the decline was $1.4 \%$ per $\mathrm{kg}$. The only significant difference in the measured body composition characteristics (height, body weight, fat mass, muscle mass) or physical performance (maximal aerobic capacity, upper and lower-body power) variables between the fast and slow performers was higher lower-body power of the fast performers measured by the vertical jump height. These findings are in close coherence with the present study. It is also noteworthy that compared to no load condition the combat load increased discomfort and, more importantly, reduced explosive strength by $25 \%$, measured by CMJ 2 before the actual performance of MST. Furthermore, CMJ2 showed a stronger correlation with DMR $\left(r_{s}\right.$ $=0.73)$ than with BM $\left(r_{s}=0.21\right)$, FATM $\left(r_{s}=-0.45\right)$ or DM $\left(r_{s}=-0.47\right)$ independently.

The present study demonstrated that BM solely is not a good predictor of the MST performance as it was not associated with the MST time. This observation is supported by the study of Bishop et al ${ }^{4}$ who found that BM explained only a minor part $(\sim 6 \%)$ of indoor obstacle course completion time. In their study, improved obstacle course performance was more strongly explained by the lower amount of body fat and higher muscle strength, endurance and power relative to BM, but also by technique and agility.

The moderate inverse correlations between SMM and MST $\left(r_{s}=-0.47, p<0.001\right)$ as well as between $\mathrm{SMM}$ and $\mathrm{CMJ} 2\left(r_{s}=-0.56, p<0.001\right)$ suggest that higher skeletal muscle mass might improve military specific anaerobic performance. The inclusion of SMM as a significant variable in the stepwise regression model supports this suggestion. On the other hand, the strength of body composition-based correlation was improved by using the DMR equation adopted from Lyons et al ${ }^{30}$. In their study, strong correlations were found between metabolic demands (relative oxygen 
consumption, $\% \mathrm{VO}_{2} \mathrm{max}$ ) and DMR with increasing external loads in the load carriage test. From the physiological perspective this seems logical. The energy consumption of the working muscles increases in relation to force output which in turn depends on the weight of the carried load in weight bearing movements ${ }^{30}$. In the present military context, the weight was formed of a combination of fat mass and combat load (=DM). A smaller DM in relation to BM leads to a lower relative energy expenditure and thus, the ability to perform MST in a shorter time. DMR was not, however, included into the regression analysis, probably due to multicollinearity with the other body composition variables.

As in any sports, the focus of military physical training should be success in the given tasks. Therefore, it is important to gain knowledge of the variables of body composition and physical performance behind that success. The present findings suggest that important characteristics of a soldier involved with combat situations are a high level of muscular power in the lower extremities, endurance capacity, large muscle mass in relation to fat mass as well as the external load carried during various assignments. A more detailed basis for optimized strength training prescription for the warfighter has been published by Kraemer and Szivak ${ }^{24}$.

The present study had some weaknesses that need to be discussed. As in all simulations, the validity, reliability and reproducibility of the test method can be questioned. The reliability and reproducibility of MST were not tested in the present study. The MST track was planned to solely evaluate the anaerobic endurance capacity of soldiers. Thus, procedures requiring specific skills and additional time to conduct (e.g. aiming, hitting a target with a grenade) were excluded from the protocol. Compared to real-life scenario, this may weaken the relevance of the test method. 
However, all scenarios are generally theoretical in nature and the selected sub-tasks in the present test model include the most typical movement patterns to soldiers involved with combat ${ }^{43}$. In addition, this was the first time for the soldiers to perform the MST and, therefore, they have not had possibilities to make, for instance, pacing strategies for their performance based on prior trials. Thus, the associations found in the present study may in fact resemble even more reliable performance predictors of suddenly changing real-life scenarios than during repeated trials.

In conclusion, BM in relation to FATM and the carried load as well as muscular power of the lower extremities seem to be good predictors of high-intensity military performance, measured by MST. Furthermore, workouts focusing on development of lower body strength and power are encouraged to be implemented to training programs designed for soldiers engaging anaerobic combat situations. In addition, basic fitness tests such as vertical jump, 3000-m run, push-ups and SMM seem to be reliable and time saving methods to assess military performance of soldiers.

\section{PRACTICAL APPLICATIONS}

The present study introduced a novel, field-expedient MST which can be utilized to estimate the high intensity anaerobic performance capacity of soldiers. The MST track can be built with minimal space and equipment requirements (Fig 1B). Previous studies have proven the utility of simple jump tests to detect performance decrements induced by intensive military training ${ }^{34,48}$. In the present study, SLJ produced nearly similar correlations as CMJ2 did with the MST time. In addition, the correlation between CMJ2 and SLJ was high. Therefore, the standing long jump could be one good possibility as a simple, field-expedient test to evaluate military relevant high-intensity task performance of soldiers, even during military operations. Furthermore, physical training specialists 
should implement workouts focusing on development of the lower body strength and power alongside with aerobic endurance. The main aim of such training programs is to improve physical performance in anaerobic combat situations.

\section{ACKNOWLEDGEMENTS}

The authors appreciate the financial support of MATINE, the Scientific Advisory Board for Defence (Finland) and the Defence Support Foundation, Ms Johanna Stenholm, Ms Mia Laakso and Ms Moona Myllyaho for their assistance in data analysis, Mr Risto Puurtinen and Mrs Aila Ollikainen for their blood and saliva analyses, and Mrs Elina Vaara for statistical analyses.

The views, opinions, and/or findings contained in this publication are those of the authors and should not be construed as an official position, policy, or decision of the Finnish Defence Forces, unless so designated by other documentation.

\section{REFERENCES}

1. American College of Sports Medicine. ACSM’s guidelines for exercise testing and prescription. 6. Edition. Philadelphia. U.S.A. Lippincott Williams \& Wilkins. 2000.

2. Angeltveit A, Paulsen G, Solberg P, Raastad T. Validity, Reliability, and Performance Determinants of a New Job-Specific Anaerobic Work Capacity Test for the Norwegian Navy Special Operations Command. J Strength Cond Res. 2016; 30(2): 487-496.

3. Billing D, Silk A, Tofari P, Hunt A. Effects of Military Load Carriage on Susceptibility to Enemy Fire During Tactical Combat Movements. J Strengh Cond Res. 2015; 29(11S): S134-S138. 
4. Bishop P, Crowder T, Fielitz L, Lindsay T, Woods A. Impact of Body Weight on Performance of a Weight-Supported Motor Fitness Test in Men. Mil Med. 2008; 173(11): $1108-1114$.

5. Blount E, Ringleb S, Tolk A, Bailey M, Onate J. Incorporation of physical fitness in a tactical infantry simulation. J Defence Model Simulation. 2011; 10: 235-246.

6. Bocanegra O, Diaz M, Teixeira R, Soares S, Espindola F. Determination of the lactate threshold by means of salivary biomarkers: chromogranin A as novel marker of exercise intensity. Eur J Appl Physiol. 2012; 112: 3195-3203.

7. Borg G. Psychophysical bases of perceived exertion. Med Sci Sports Exerc. 1982; 14: 377381.

8. Bosco C, Luhtanen P, Komi P. A simple method for measurement of mechanical power in jumping. Eur J Appl Physiol Occup Physiol. 1983; 50(2): 273-282.

9. Carlson M, Jaenen S. The development of a preselection physical training program for Canadian special operations regiment applicants. J Strength Cond Res. 2012; 26(7): S2-S14.

10. Carstairs G, Ham D, Savage R, Best S, Beck B, Doyle T. A Box Lift and Place Assessment is Related to Performance of Several Military Manual Handling Tasks. Mil Med. 2016; 181(3): 258-264. doi: 10.7205/MILMED-D-15-00070.

11. Charlton S, Orr R. The Impact of Occupational Load Carriage on Carrier Mobility: A Critical Review of the Literature. International Journal of Occupational Safety and Ergonomics (JOSE) 2014; 20(1): 33-41.

12. Chicarro J, Perez M, Carvajal A, Bandres F, Lucia A. The salivary amylase, lactate and EMG response to exercise. Jpn J Physiol 1999; 49(6): 551-554.

13. Crawford K, Fleishman K, Abt J, Sell T, Lovalekar M, Nagai T, Deluzio J, Rowe R, McGrail M, Lephart S. Less body fat improves physical and physiological performance in army soldiers. Mil Med. 2011; 176(1): 35-43. 
14. De Oliveira V, Bessa A, Lamounier R, de Santana M, de Mello M Espindola F. Changes in the salivary biomarkers induced by an effort test. Int J Sports Med. 2010; 31: 377-381.

15. Erdman J, Bistrian B, Clarkson P, Dwyer J, Klein B, Lane H, Manore M, O`Neil P, Russell R, Tepper B, Tipton K, Yates A. Nutrient composition of rations for short-term, highintensity combat operations. Washington, DC.The National Academies Press. 2006.

16. Friedl K, Knapik J, Häkkinen K, Baumgartner N, Groeller H, Taylor N, Duarte A, Kyröläinen H, Jones B, Kraemer W, Nindl B. Perspectives on aerobic and strength influences on military physical readiness: Report of an international military physiology roundtable. J Strength Cond Res. 2015; 29(11S): S10-S23.

17. Harman E, Gutekunst D, Frykman P, Sharp M, Nindl B, Alemany J, Mello R. Prediction of simulated battlefield physical performance from field-expedient tests. Mil Med. 2008; 173(1): 36-41.

18. Häkkinen K, Alen M, Kallinen M, Izquierdo M, Jokelainen K, Lassila H, Mälkiä E, Kraemer W, Newton R. Muscle CSA, force production, and activation of leg extensors during isometric and dynamic actions in middle-aged and elderly men and women. J Aging Phys Act. 1998; 6: 232-247.

19. Jaworski R, Jensen A, Niederberger B, Congalton R, Kelly K. Changes in Combat task Performance Under Increasing Loads in Active Duty Marines. Mil Med. 2015; 180(3): 179_ 186.

20. Khaustova S, Shkurnikov M, Tonevitsky A. Short highly intense exercise causes changes in salivary concentrations of hydrocortisone and secretory IgA. Bull Exp Biol Med. 2010; 149(5): 569-573.

21. Knapik J, Reynolds K, Harman E. Soldier Load Carriage: Historical, Physiological, Biomedical, and Medical Aspects. Mil Med. 2004; 169 (1): 45-56. 
22. Knapik J, Sharp M, Darakjy S, Jones S, Hauret K, Jones B. Temporal changes in the physical fitness of US Army recruits. Sports Med. 2006; 36(7): 613-634.

23. Kraemer W, Fleck S, Deschenes M. Exercise Physiology. Integrating Theory and Application. 2. International edition. China. Wolters Kluwer. 2016. pp 27-74.

24. Kraemer W, Szivak T. Strength training for the warfighter. J Strength Cond Res. 2012; 26(7): S107-S118.

25. Kusano M, Vanderburgh P, Bishop P. Impact of body size on women's military obstacle course performance. Biomed Sci Instrum. 1997; 34: 357-362.

26. Laing-Treloar A, Billing D. Effect of load carriage on performance of an explosive, anaerobic military task. Mil Med. 2011; 176(9): 1027-1031.

27. Larsen B, Netto K, Aisbett B. The effect of body armor on performance, thermal stress and exertion: A critical review. Mil Med. 2011; 176(11): 1265-1273.

28. Larsen B, Netto K, Skovli D, Vincs K, Vu S, Aisbett B. Body Armor, Performance, and Physiology During Repeated High-Intensity Work Tasks. Mil Med. 2012; 177(11): 13081315.

29. Loturco I, D’Angelo R, Fernandes V, Gil S, Kobal R, Cal Abad C, Kitamura K, Nakamura F. Relationship between sprint ability and loaded/unloaded jump tests in elite sprinters. J Strength Cond Res. 2015; 29(3): 758-764.

30. Lyons J, Allsopp A, Bilzon J. Influences of body composition upon the relative metabolic and cardiovascular demands of load-carriage. Occup Med (Lond). 2005; 55(5): 380-384.

31. Mala J, Szivak T, Flanagan S, Comstock B, Laferrier J, Maresh C, Kraemer W. The role of strength and power during performance of high intensity military tasks under heavy load carriage. US Army Med Dep J. 2015; Apr-Jun: 3-11.

32. Martin P, Nelson R. The effect of carried loads on the combative movement performance of men and women. Mil Med. 1985; 150(7): 357-362. 
33. Nindl B, Alvar B, R Dudley J, Favre M, Martin G, Sharp M, Warr B, Stephenson M, Kraemer W. Executive Summary From the National Strength and Conditioning Association's Second Blue Ribbon Panel on Military Physical Readiness: Military Physical Performance Testing. J Strength Cond Res. 2015; 29(Suppl 11): S216-220. doi: 10.1519/JSC.0000000000001037.

34. Nindl B, Leone C, Tharion W, Johnson R, Castellani J, Patton J, Montain J. Physical performance responses during $72 \mathrm{~h}$ of military operational stress. Med Sci Sports Exerc. 2002; 34(11): 1814-1822.

35. O`Neal E, Hornsby J, Kelleran K. High-Intensity Tasks with External Load in Military Applications: A Review. Mil Med. 2014; 179(9): 950-954.

36. Paccotti P, Minetto M, Terzolo M, Ventura M, Ganzit G, Borrione P, Termine A, Angeli A. Effects of high-intensity isokinetic exercise on salivary cortisol in athletes with different training schedules: relationships to serum cortisol and lactate. Int J Sports Med. 2005; 26(9): $747-755$.

37. Payne W, Harvey J. A framework for the design and development of physical employment tests and standards. Ergonomics. 2010; 53(7): 858-871. doi: $10.1080 / 00140139.2010 .489964$

38. Richmond V, Rayson M, Wilkinson D, Carter J, Blacker S, Nevill A, Ross J, Moore S. Development of an operational fitness test for the Royal Air Force. Ergonomics. 2008; 51(6): 935-946. doi: 10.1080/00140130801939725.

39. Rohde U, Sievert A, Rüther T, Witzki A, Leyk D. Concept for a Predeployment Assessment of Basic Military Fitness in the German Armed Forces. J Strength Cond Res. 2015; 29(Suppl 11): S211-215. doi: 10.1519/JSC.0000000000001074.

40. Santtila M, Häkkinen K, Kraemer W, Kyröläinen H. Effects of Basic Training on Acute Physiological Responses to a Combat Loaded Run Test. Mil Med. 2010; 175(4): 273-29. 
41. Santtila M, Kyröläinen H, Vasankari T, Tiainen S, Palvalin K, Häkkinen A, Häkkinen K. Physical fitness profiles in young Finnish men during the years 1975-2004. Med Sci Sports Exerc. 2006; 38(11): 1990-1994.

42. Sharp M, Patton J, Vogel J. A database of physically demanding tasks performed by U.S. army soldiers. Military Performance Division. Army Research Inst of Environmental Medicine, Natick MA. 1998 (Technical Report):T98. Available at: http://www.dtic.mil/dtic/tr/fulltext/u2/a338922.pdf. Accessed October 22, 2016.

43. Silk A, Billing D. Development of a Valid Simulation Assessment for a Military Dismounted Assault Task. Mil Med. 2013; 18(3): 315-320.

44. Taylor N, Groeller H. Work-based physiological assessment of physically-demanding trades: a methodological overview. J Physiol Anthropol Appl Human Sci. 2003; 22(2): 7381.

45. Vanderburg P, Crowder T. Body Mass Penalties in the Physical Fitness Tests of the Army, Air Force, and Navy. Mil Med. 2006; 171(8): 753-756.

46. Vanderburg P. Occupational Relevance and Body Mass Bias in Military Physical Fitness Tests. Med Sci Sport Exerc. 2008; 40(8): 1538-1545.

47. Viljanen T, Viitasalo JT, Kujala UM. Strength charasteristics of a healthy urban adult population. Eur J Appl Physiol Occup Physiol. 1991; 63(1): 43-47.

48. Welsh T, Alemany J, Montain S, Frykman P, Tuckow A, Young A, Nindl B. Effects of intensified military field training on jumping performance. Int J Sports Med. 2008; 29(1): $45-52$. 


\section{TABLES}

Table 1. Mean ( \pm SD and range) values of the body composition and physical fitness variables of the soldiers.

\begin{tabular}{|l|c|c|c|c|c|}
\hline Variable & Mean & SD & Min & Max & $\boldsymbol{n}$ \\
\hline SMM (kg) & 39.1 & 4.3 & 30.0 & 49.2 & 81 \\
\hline FATM (kg) & 11.0 & 4.8 & 2.9 & 31.5 & 81 \\
\hline FAT\% & 13.7 & 5.0 & 3.6 & 31.5 & 81 \\
\hline MVC $_{\text {lower }}(\mathrm{N})$ & 4238 & 922 & 2246 & 6563 & 81 \\
\hline MVC $_{\text {upper }}(\mathrm{N})$ & 1139 & 227 & 716 & 1736 & 81 \\
\hline SLJ (cm) & 235 & 24 & 174 & 300 & 80 \\
\hline CMJ1 (cm) & 38 & 6 & 23 & 54 & 81 \\
\hline Sit-ups (reps/min) & 46 & 10 & 20 & 64 & 81 \\
\hline Push-ups (reps/min) & 41 & 13 & 10 & 78 & 81 \\
\hline Pull-ups (rep max) & 10 & 5 & 0 & 20 & 81 \\
\hline 3000 m run (s) & 835 & 87 & 636 & 1106 & 81 \\
\hline
\end{tabular}

SMM, skeletal muscle mass; FATM, fat mass; MVClower, maximal voluntary contraction of the lower extremities; MVCupper, maximal voluntary contraction of the upper extremities; SLJ, standing long jump; CMJ, counter movement jump.

Table 2. Mean $( \pm \mathrm{SD})$ acute changes in saAA, saCOR, RPE, BLa and CMJ induced by MST.

\begin{tabular}{|l|c|c|c|c|c|}
\hline Variable & Pre & Post & \% change & $\boldsymbol{p}$ & $\boldsymbol{n}$ \\
\hline saAA $(\mathrm{U} \cdot \mathrm{mL})$ & $66 \pm 66$ & $179 \pm 166$ & $306 \pm 321$ & $<0.001$ & 68 \\
\hline saCOR $(\mathrm{nmol} \cdot \mathrm{L})$ & $13.9 \pm 6.2$ & $14.9 \pm 6.8$ & $12 \pm 49$ & 0.332 & 65 \\
\hline $\mathrm{RPE}(6-20) *$ & $12 \pm 2$ & $18 \pm 1$ & $81 \pm 42$ & $<0.001$ & 81 \\
\hline $\mathrm{BLa}(\mathrm{mmol} \cdot \mathrm{L})$ & $2.6 \pm 1.5$ & $10.8 \pm 3.7$ & $414 \pm 294$ & $<0.001$ & 57 \\
\hline $\mathrm{CMJ}(\mathrm{cm}) * *$ & $28.5 \pm 5.1$ & $27.0 \pm 5.0$ & $-5 \pm 9$ & $<0.001$ & 81 \\
\hline
\end{tabular}


saAA, saliva alpha-amylase; saCOR, saliva cortisol; RPE, rating of perceived exertion; BLa, blood lactate; CMJ, countermovement jump; MST, military simulation test. *, both RPE values estimated in combat load; **, both jumps performed in combat load.

Table 3. Associations between the measured variables and MST.

\begin{tabular}{|l|c|c|c|}
\hline Variable & $\boldsymbol{r}_{\boldsymbol{s}}$ & $\boldsymbol{p}$ & $\boldsymbol{n}$ \\
\hline DMR (kg) & -0.669 & $<0.001$ & 81 \\
\hline CMJ2 (cm) & -0.659 & $<0.001$ & 81 \\
\hline SLJ (cm) & -0.616 & $<0.001$ & 80 \\
\hline CMJ3 (cm) & -0.614 & $<0.001$ & 81 \\
\hline CMJ1 (cm) & -0.595 & $<0.001$ & 81 \\
\hline Sit-ups (reps/min) & -0.546 & $<0.001$ & 81 \\
\hline FAT\% & -0.534 & $<0.001$ & 81 \\
\hline Push-ups (reps/min) & -0.533 & $<0.001$ & 81 \\
\hline MVC upper (N) & -0.485 & $<0.001$ & 81 \\
\hline 3000 m run (s) & 0.483 & $<0.001$ & 81 \\
\hline SMM (kg) & -0.474 & $<0.001$ & 81 \\
\hline MVC lower (N) & -0.454 & $<0.001$ & 81 \\
\hline Pull-ups (rep max) & -0.435 & $<0.001$ & 81 \\
\hline DW (kg) & 0.427 & $<0.001$ & 81 \\
\hline FATM (kg) & 0.403 & $<0.001$ & 81 \\
\hline Body height (cm) & -0.384 & $<0.001$ & 81 \\
\hline BM (kg) & -0.183 & $n .5$. & 81 \\
\hline DMR, dead & & & 8 \\
\hline
\end{tabular}

DMR, dead mass ratio; BM, body mass; CMJ, counter movement jump; SLJ, standing long jump; MVCupper, maximal voluntary contraction of the upper extremities; SMM, skeletal muscle mass; MVClower, maximal voluntary contraction of the lower extremities; DM, dead mass; FATM, fat mass; BM, body mass. 


\section{FIGURES}

Figure 1. Schematic illustration (A) and technical graph (B) of the military simulation test (MST) track.

A)

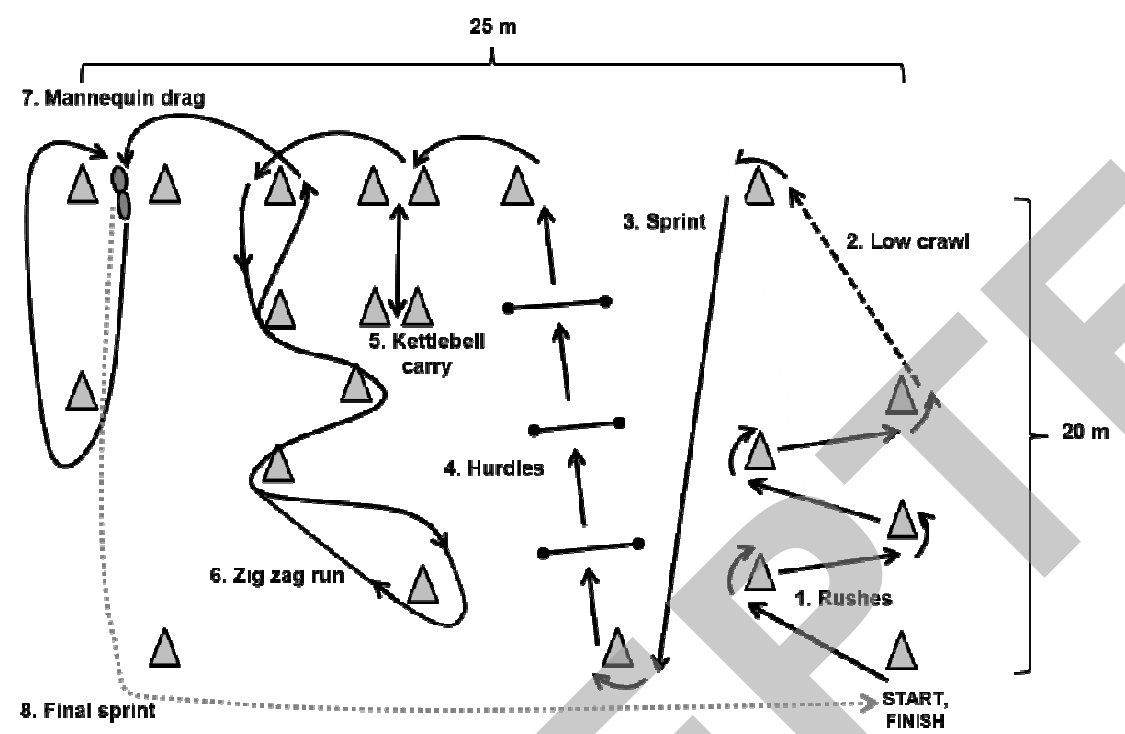

B)

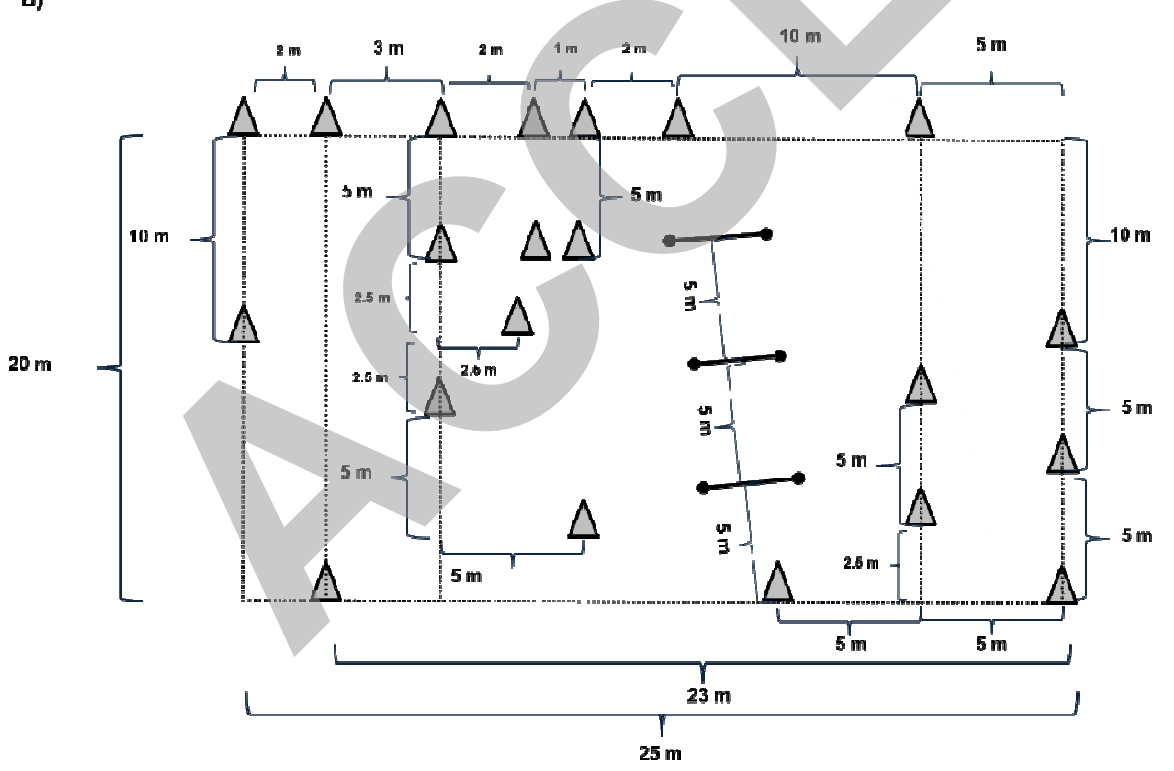

MST equipment: 20 plastic cones; 3 hurdles, height $40 \mathrm{~cm} /$ hurdle; 4 kettlebells, weight 16 $\mathrm{kg} / \mathrm{kettlebell;} \mathrm{mannequin,} \mathrm{total} \mathrm{weight} 65 \mathrm{~kg}$; tape measure, $25 \mathrm{~m}$. 
Figure 2. Countermovement jump height, performed with a combat load excluding the assault rifle replica (CMJ2), plotted against military simulation test (MST) time.

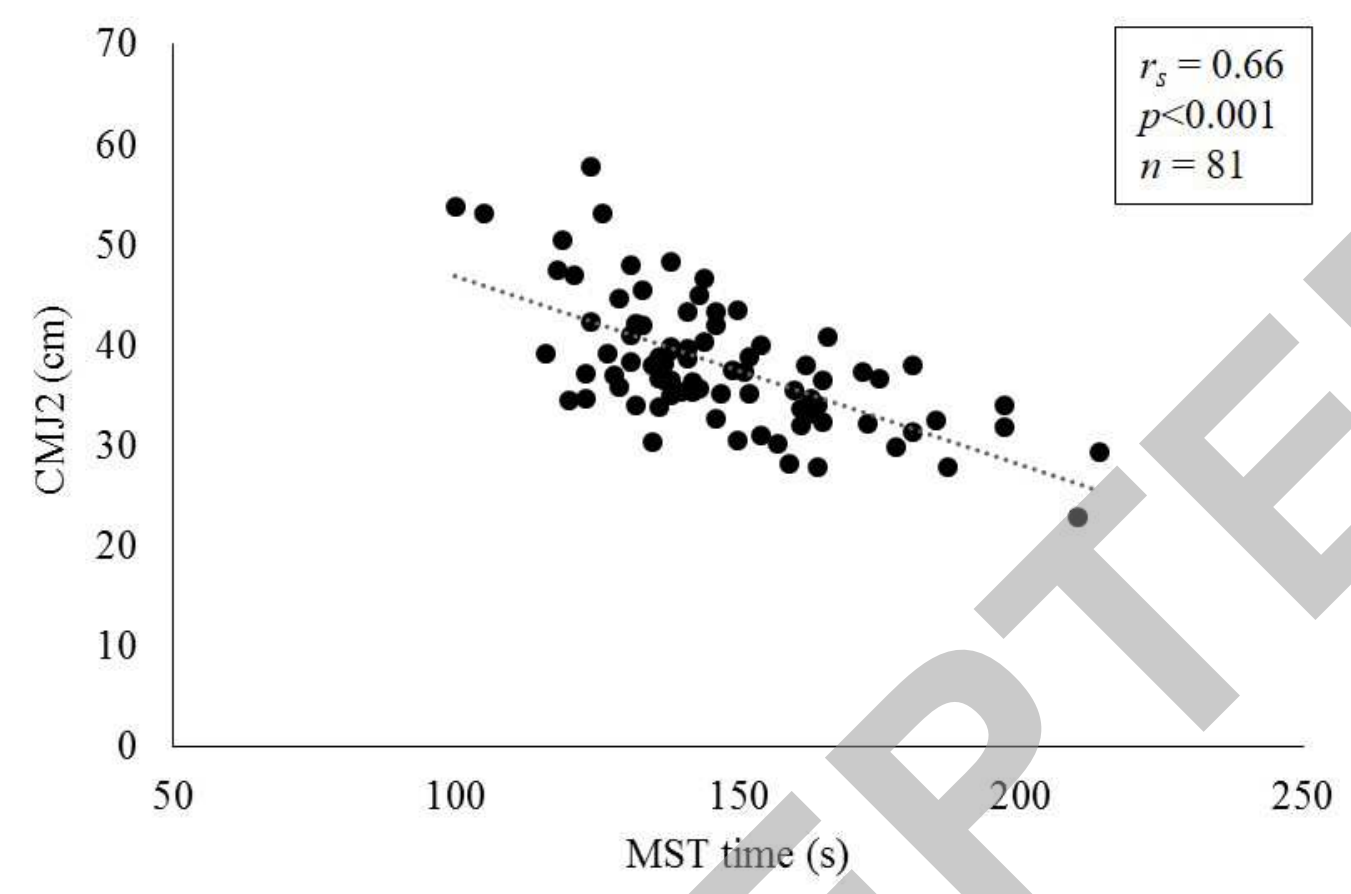

Figure 3. Dead mass ratio (DMR) plotted against the military simulation test (MST) time.

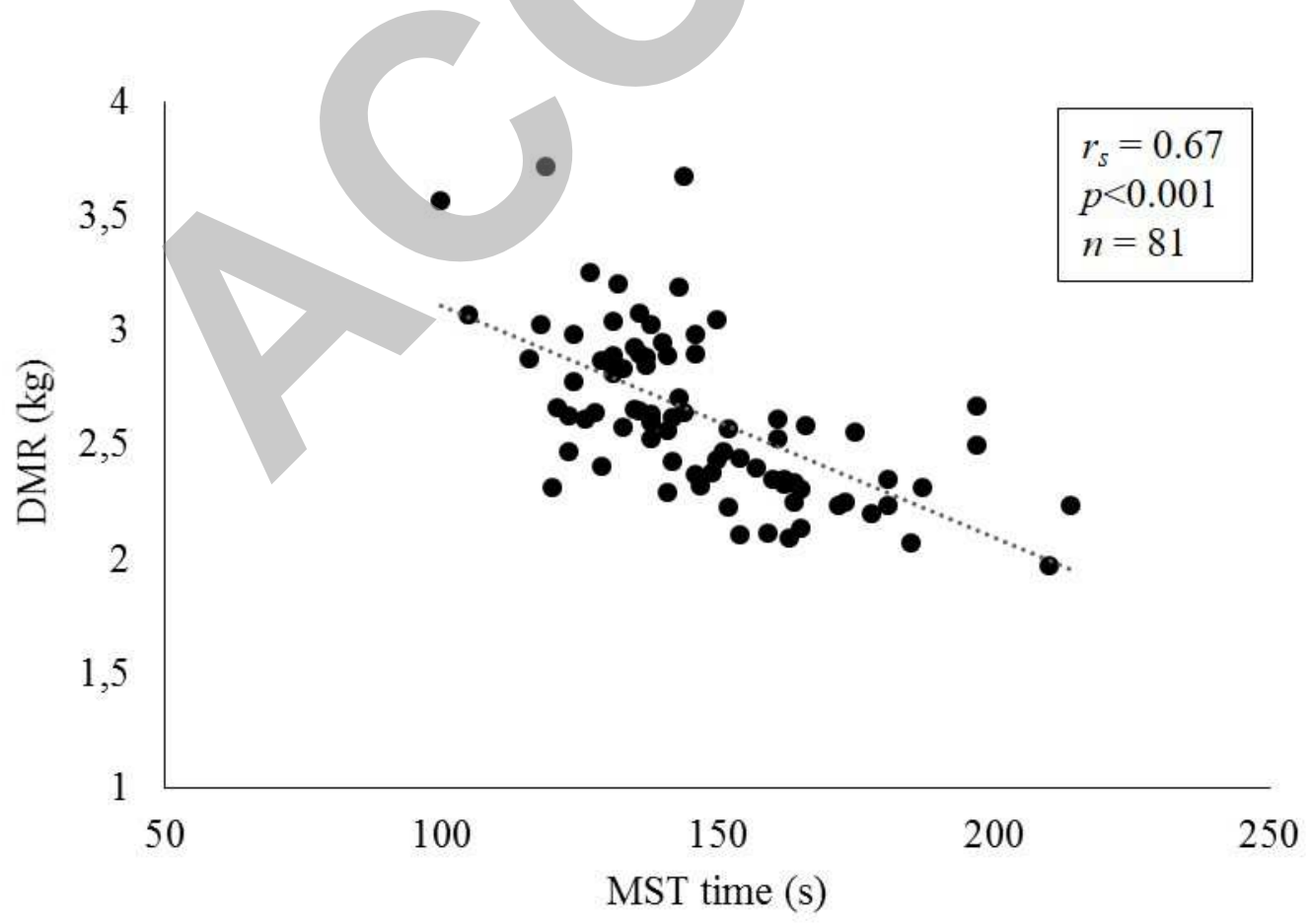

